\title{
CONFIGURATION AND DEFORMATION CONTROL OF A HYBRID CABLE BENDING-ACTIVE STRUCTURE
}

\author{
O. KONTOVOURKIS, M.C. PHOCAS, K.C. ALEXANDROU \& S. FRANGOGIANNOPOULOS \\ Department of Architecture, University of Cyprus, Cyprus.
}

\begin{abstract}
Reconfigurable structural systems aim at spatial adaptability in respect to changing functional, aesthetic or other architecture-oriented objectives. At the same time, adaptive systems are called to reserve the structure's load-bearing capacity according to external loading criteria and scenarios. While pantograph structures have proven promising in these critical aspects, bending-active elements discard multiple local hinges and number of members by replacing them with single members of enhanced elastic bending deformability. This soft approach renders the possibility to form complex-, single- or double-curved primary structures from straight or planar members, providing in this respect an alternative framework to realize constructions of increased transformability and diversity in forms. The development of hybrid systems composed of bending-active members using secondary cables as means of stability and control, enables adjustability of the systems' form-found shape and deformation control. In the current paper, a hybrid cable bending active structure is investigated at the level of prototype unit and overall structure. On the horizontal plane, the unit consists of a pair of vertically oriented PTFE lamellas, interconnected at mid-length and deformed in inverse direction to form a curvilinear symmetric shape. Cable and strut elements stabilize the primary elastic members by connecting them at both ends in longitudinal and transverse direction, respectively. The overall structure acquires three arc-like configurations, controlled by the secondary system of cables and struts positioned at the periphery of the primary system's span. All systems are examined in their form-finding and load-bearing behaviour. Keywords: adaptive systems, hybrid cable bending-active structures, soft mechanical approach.
\end{abstract}

\section{INTRODUCTION}

The invention of kinematics during the turn of the nineteenth century triggered a new dimension of possibilities and prospects in the field of mechanics and machine design [1]. The selection of rigid elements with mechanical properties of low elastic modulus, fastened together in constrained movable conditions, enabled the conceptualization of genuine mechanical lever elements [2]. To an extent, a chain of elements can result in composite mechanisms of particular kinetic behaviour. The design toolbox developed remains a fundamental source for the synthesis of modest or complex kinetic systems, able to exhibit characteristics of advanced dynamic behaviour and capacity [3]. In architecture, implemented examples that have esteemed the prosperities of this invention, gave birth to well-known deployable systems, such as pantographs, tensegrities, tensile and several other hybrid systems [4]. The ability of a structural system to reconfigure itself and deliver alternative configurations prompted an architecture with radical adaptive attributes, in terms of functional, aesthetic, ecological, or environmental means [5]. Furthermore, deployability gave additional credits to adaptive features, that of transportability, mobility and flexibility [6]. In terms of structural design and construction, modularity, connectivity and self-weight minimisation compose the main agenda of ideals and standards that formed the development and further optimization of their design [7]. In juxtaposition to the above, implemented reconfigurable systems followed by such hard mechanical approach have often proven to suffer from unsustainable and low-efficiency features. In most of the cases, the plethora of constituent elements, connection details and the amount of assembly duration results in complex and costly construction processes. The implementation of mechanical actuators for structural 
reconfiguration, or real-time kinetic control, needs further improvements in terms of optimization of the resulting kinetic systems [8].

On dealing with the above complications, recent research activities focus on an alternative soft approach that is able to realize kinematics in a fundamentally different way [9]. Compared to the hard mechanical approach, the former suggests the use of pliable materials with high elastic modulus that is able to perform transformation through the member's elastic deformations. Slender members with initial planar or straight cross-section can generate a variety of deformed shapes of single or multi-curved surfaces through active bending [10]. The embedded energy stored inside the material's molecular structure, allows bending-active members to compose autonomous kinetic mechanisms that are able to undergo geometrical deformation without the empowerment of additional energy [11]. The deformation process can increase the member's stiffness at a local level and establish sufficient stabilization on a global scale [12].

The design of adaptive structural systems using active bending as a generative agent necessitates form-finding during the assembly and configuration stages. Complex arrangements of elastically bendable members can result in unforeseen distorted geometries and unexpected deformation actions. In this respect, former examples that familiarized with the soft mechanical principles used experimental models or similar techniques, such as the hanging chain model [13], to gain insight into the final force equilibrated outcome and deformation process. Nowadays, several calculation techniques have been developed [14], which are able to provide the form-found shape through soft transformation.

Implemented examples from the recent past, have chosen the soft approach, mainly for economic reasons. The majority of these cases are gridshell structures in timber [15]. An indicative project is the Manheim multi-hall constructed in Germany by Frei Otto in 1975 [16]. The shell structure is assembled from rectangular timber sections, cross-fastened together in the planar state and potentially bended to form the overall gridshell's organic shape using the "push-up" technique. This technique however does not comply with current regulations due to multiple parameters, such as the lack of controllability during the deformation process and, more importantly, due to concentrated stress development in partial areas within the structure, resulting in breakages of laths or joints. Nowadays, different construction techniques exist, among others, the "pull-up" technique, applied via the use of scaffolding infrastructural support, cranes and robes or large inflatable balloons installed beneath the non-deformed grid, forcing the overall assembly to deform and reach its target shape [17].

In the current paper, a hybrid cable bending-active structural prototype is presented. Form-finding of the system has been investigated by applying Finite-Element Analysis (FEA). At the preliminary stage, the system is prestressed in a linear direction using cables of closed circuit. Secondary cables are installed on the periphery of the primary structure, in order to provide the final arc-like shape of the assembly system through their own length modification. Three different system configurations are examined in their form-finding process and load-bearing behaviour under a vertical uniform distributed load of $2.5 \mathrm{kN} / \mathrm{m}$. Results obtained describe the geometrical deformation and inner stresses, developed in both bending-active and tension-only members, during all stages of assembly and external loading.

\section{STRUCTURAL COMPOSITION}

The design development of the structure is based on the investigation of a primary unit component, originating from the synergic action of a pair of bending-active and tension-only members. The aim is to achieve an analogously deformable unit as shown in Fig. 1, realised 
by the reversible geometrical deformability of the elastic stripes and stabilized by primary cables (PC). At a further stage, six consecutively connected units, assembled in linear arrangement, are used to construct the overall system. The system's overall arc-like configurations, A, B and C, are stabilized through secondary cables (SC) and struts located at the periphery of the systems. The overall form-finding stage follows a step-by-step deformation process realized through the secondary cables' length modification.

The elastic stripes are assigned to the PTFE material characteristics (E: $\left.2.6 \times 10^{6} \mathrm{GPA}\right)$ and have initially an absolutely planar shape with dimensions of 2,800/300/15 mm (L/W/T). The lamellas are placed with their strong axis parallel to the vertical plane and are interconnected at mid-length. Primary cables are assigned to prestressing steel Y1770 with diameter of 20 $\mathrm{mm}$, and articulately joined at the elastic members' endpoints. The units may form multiple equilibrium states depending on the cable's length modification, Fig. 1. Case no. 2 in Fig. 1, with unit's boundary dimensions of $0.8 \times 2.4 \mathrm{~m}^{2}$ has been selected for the composition of the system, yielding approximately $100 \mathrm{kN}$ axial force in the primary cables.

The overall structure is composed of six consecutively connected units assembled in linear arrangement, resulting in a non-deformed length of $16 \mathrm{~m}$. Prior to applying the secondary members, horizontal struts are added to the primary structure, in between each consecutive unit, for stability purposes.

The secondary structure is composed of steel struts, with dimensions of 1,000/75/15 mm (L/D/T), and cables with diameter of $20 \mathrm{~mm}$. Each strut is placed vertically, between two consecutive units. The cables are articulately connected on the struts' end-points and ground supports, Fig. 2. Following activation of the secondary cables, the prestressed units deform further in a transverse direction, allowing the system to reach its final arc-like shape.

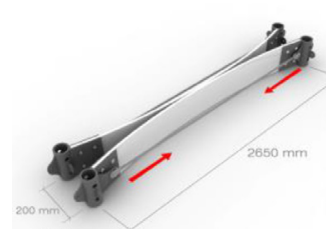

(a)
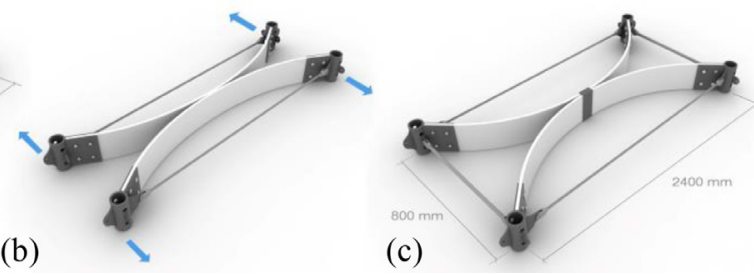

Figure 1: Horizontal unit's deformation pattern; (a) Slightly deformed shape; (b) case 1: cable shrinkage, $300 \mathrm{~mm}$; (c) case 2: cable shrinkage $500 \mathrm{~mm}$.
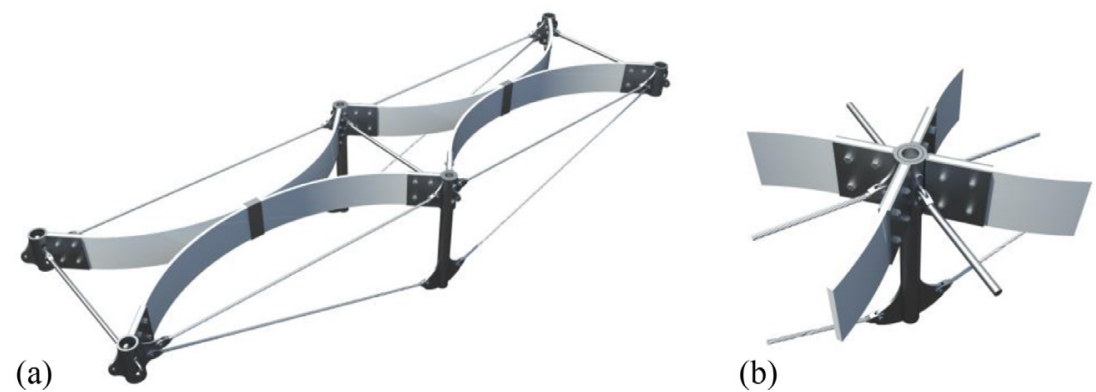

(b)

Figure 2: Structural details; (a) Typical assembly; (b) Joint detail. 


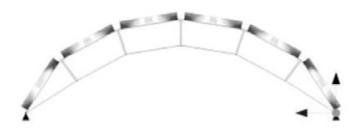

(a)

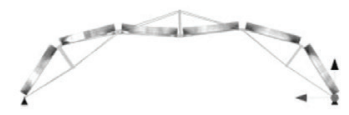

(b)

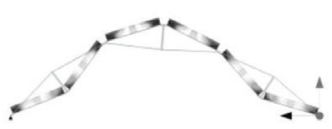

(c)

Figure 3: System arc-like configurations at assembly stage; (a) Configuration A; (b) Configuration B; (c) Configuration C.

The position of the strut members of the secondary system as to the primary members plays a critical role on the overall structure's shape. This is due to the resulting secondary cable routes and the connections to the primary system. In this respect, three configurations with differentiated orientation of the strut elements are defined, resulting in distinctive arclike configurations.

Configuration A: The first structural system as shown in Fig. 3a demonstrates an arc-like shape in elevation. This is achieved by positioning all strut elements facing the inner side of the structure. Secondary cables' length modifications amount to $300 \mathrm{~mm}$, resulting in the primary structure's deformation in a vertical direction.

Configuration B: This system shows a more complex configuration with a stronger primary system's curvature near the supports. Struts are only placed at nodes 1, 3 and 5. At nodes 1 and 5 , struts are placed in the inner side of the system, and exterior side at node 3 . The secondary cable's length modification amounts to $500 \mathrm{~mm}$. The resulting deformation of the primary structure is demonstrated in Fig. $3 \mathrm{~b}$.

Configuration C: The third system in Fig. $3 \mathrm{c}$ is exactly the opposite to configuration B. Strut elements in nodes 1, 3 and 5 are oriented in the opposite direction. This configuration has maximum height compared to the previous configurations.

\subsection{Form-finding}

The FEA method has been selected for the simulation of the assembly stages and load-bearing analysis of the system. Compared to alternative form-finding techniques, FEA takes into account critical aspects, such as the materials' mechanical and physical characteristics. In extent, the analysis conducted takes into account material and geometrical non-linearities that are characteristic principles of the elastic members. The analysis of the proposed system has been geometrically modelled in McNeel Rhinoceros ${ }^{\circledR}$ and further analyzed with the static analysis software Sofistik Structural Desktop®.

The form-finding investigation of the systems is divided into two stages. At the completion of each stage, all internal stresses produced are stored within the members and transferred to the subsequent analysis stage in the form of a primary load case. This is performed via Teddy, a text command module of Sofistik, which allows custom programming of analysis sequence and conditions [18]. At each stage, a particular action of a group of elements is enabled. Ideal commands provided by Sofistik tool case is the cables' length modification.

In the first stage of the analysis, the six linearly arranged units with total length of $16 \mathrm{~m}$ are deformed using cable shrinkage values of $300 \mathrm{~mm}$. As a result, interconnected stripe pairs (primary unit) are forced to deform and reach final symmetric shapes of $0.8 \times 2.4 \mathrm{~m}^{2}$. Consequently, the span of the primary system shrinks from 16 to $15 \mathrm{~m}$.

In the subsequent stage of analysis, all members of the structural assembly are now considered. Shrinkage values, varying from 300 to $500 \mathrm{~mm}$, are introduced for all cables of the secondary system. Due to the eccentricity of the applied force, the primary structure is forced 
to deform in the vertical direction through torsional deformation of the elastic members. The cable shrinkage values vary respectively, in order to maintain the same deformed system span of $12.5 \mathrm{~m}$ in all configurations.

\section{NUMERICAL ANALYSIS}

Results obtained from the static analysis describe the structural behaviour of the hybrid cable bending-active systems for all stages of the form-finding process, Figs 4-6 and Tables 1 and 2 . In the preliminary stage, the tension forces developed in the primary cables and the bending moments of the elastic stripes of the primary system are derived. In stage 2 of the systems' assembly, the magnitude and distribution of both, primary and secondary cables, maximum tension forces are investigated, in order to interpret the role of the members with regard to the resulting bending prestress of the elastic members. Finally, the form-found arc-like configurations are compared in terms of their load-bearing behaviour under a vertical uniformly distributed load of $2.5 \mathrm{kN} / \mathrm{m}$, Tables 1 and 2 .

In all cases, in the first stage of assembly, the maximum bending moment of the elastic members amounts to $76.34 \mathrm{kNm} / \mathrm{m}$. The primary cables' maximum axial force amounts to $108.9 \mathrm{kN}$. The distribution of axial forces is similar in all pairs of cables.

In the second stage of the assembly, the maximum bending moment of the three system configurations increases at a percentage of 17,36 and $18 \%$, respectively, taking values of $89.27,104.16$ and $89.74 \mathrm{kNm} / \mathrm{m}$. The primary cables' axial forces vary by $-28,41 \%$ and $-20 \%$ respectively. The secondary cables have maximum tension forces of $60.74,69.78$ and $88.47 \mathrm{kN}$ respectively. System configurations A and B have a different behaviour compared to that of configuration C. The primary cables' axial force decreases at 28 and $20 \%$, while in configuration $\mathrm{C}$ it increases by $41 \%$. This is due to the global curvature of the system shape that enables the secondary cables to recover part of the bending prestress stored in the elastic members. Furthermore, the amount of axial forces developed in the secondary cables is also related to the torsional deformations of the elastic stripes in the second stage of the assembly (i.e. Aii/Bii/Cii).

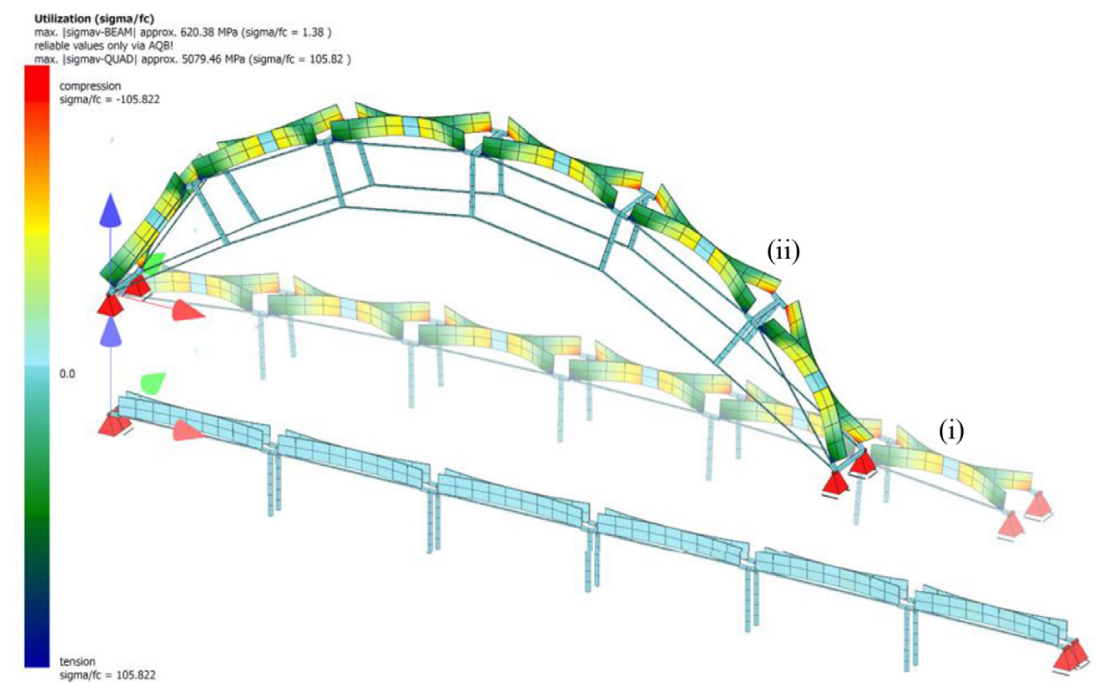

Figure 4: System configuration A non-deformed shape; (i) Linear deformation (primary structure only); (ii) Arc-like configuration (entire structure). 


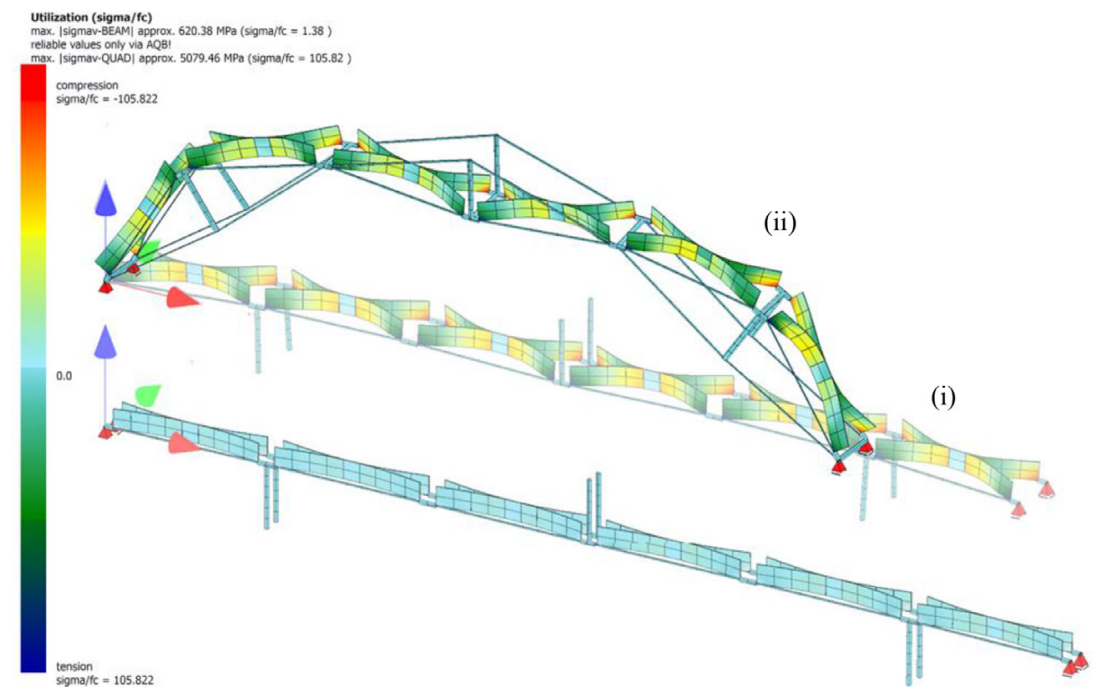

Figure 5: System configuration B non-deformed shape; (i) Linear deformation (primary structure only); (ii) Arc-like configuration (entire structure).

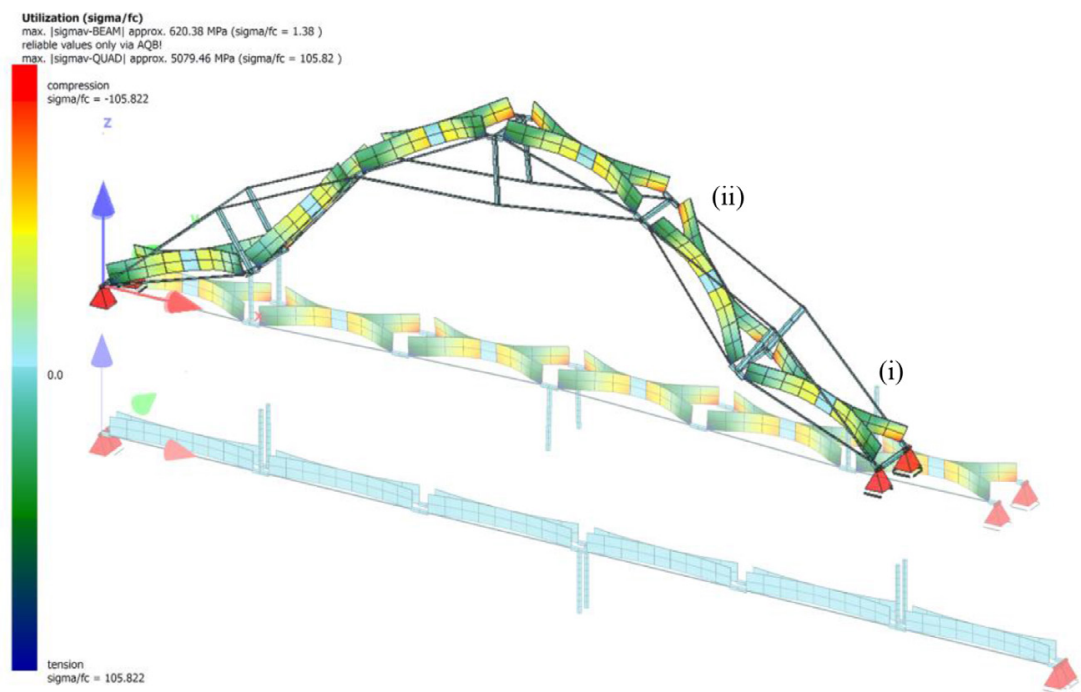

Figure 6: System configuration C non-deformed shape; (i) Linear deformation (primary structure only); (ii) Arc-like configuration (entire structure).

Further critical in the second stage of the assembly is the differentiation of the distribution of the axial force in the primary and secondary cables. The cables that are close to the supports develop considerable higher axial forces. In all cases, the primary cables that are close to the supports develop 43, 308 and $267 \%$ higher axial forces compared to the ones located at midspan (i.e. C1-C3). The same applies for the secondary cables with respective differentiation of 156,135 and $300 \%$. 
Table 1: Systems' deformations and inner forces.

\begin{tabular}{lcccccc}
\hline $\begin{array}{l}\text { System configuration } \\
\text { stage }\end{array}$ & $\mathrm{U}_{\mathrm{x}}[\mathrm{mm}]$ & $\mathrm{U}_{\mathrm{y}}[\mathrm{mm}]$ & $\mathrm{U}_{\mathrm{z}}[\mathrm{mm}]$ & $\begin{array}{c}\mathrm{M}_{\mathrm{YY}} \\
{[\mathrm{kNm} / \mathrm{m}]}\end{array}$ & $\mathrm{N}_{\mathrm{PC}}[\mathrm{kN} / \mathrm{m}] \mathrm{N}_{\mathrm{SC}}[\mathrm{kN} / \mathrm{m}]$ \\
\hline $\mathrm{A}_{\mathrm{i}}$ & $-1,000$ & 800 & 0 & 76.34 & 108.93 & Disabled \\
$\mathrm{A}_{\mathrm{ii}}$ & $-2,500$ & - & 3,450 & 89.27 & 78.38 & 60.74 \\
$\mathrm{~A}_{\mathrm{v}}$ & - & - & -10.69 & 87.61 & 79.25 & 58.72 \\
$\mathrm{~B}_{\mathrm{i}}$ & $-1,000$ & 800 & 0 & 76.34 & 108.93 & Disabled \\
$\mathrm{B}_{\mathrm{ii}}$ & $-2,500$ & - & 3,463 & 104.16 & 153.73 & 69.78 \\
$\mathrm{~B}_{\mathrm{v}}$ & - & - & -2.35 & 103.78 & 156.11 & 71.01 \\
$\mathrm{C}_{\mathrm{i}}$ & $-1,000$ & 800 & 0 & 76.34 & 108.93 & Disabled \\
$\mathrm{C}_{\mathrm{ii}}$ & $-2,500$ & - & 3,680 & 89.74 & 87.65 & 88.47 \\
$\mathrm{C}_{\mathrm{v}}$ & - & - & -7.85 & 89.57 & 87.65 & 90.30 \\
\hline
\end{tabular}

Table 2: Cables' axial forces in assembly stages.

\begin{tabular}{|c|c|c|c|c|c|c|c|}
\hline \multirow{2}{*}{$\begin{array}{l}\text { System Configuration } \\
\text { Stage }\end{array}$} & \multirow[b]{2}{*}{ Cable } & \multicolumn{6}{|c|}{ Cable Normal Force $[\mathrm{kN}]$} \\
\hline & & $\mathrm{C}_{1}$ & $\mathrm{C}_{2}$ & $\mathrm{C}_{3}$ & $\mathrm{C}_{4}$ & $\mathrm{C}_{5}$ & $\mathrm{C}_{6}$ \\
\hline \multirow{2}{*}{$\mathrm{A}_{\mathrm{i}}$} & $\mathrm{PC}$ & 103.91 & 104.88 & 106.25 & 108.93 & 104.81 & 106.55 \\
\hline & $\mathrm{SC}$ & \multicolumn{6}{|c|}{ Disabled } \\
\hline \multirow[t]{2}{*}{$\mathrm{A}_{\mathrm{ii}}$} & $\mathrm{PC}$ & 74.81 & 58.82 & 54.00 & 54.62 & 54.70 & 78.38 \\
\hline & $\mathrm{SC}$ & 60.74 & 23.26 & 23.68 & 24.34 & 22.68 & 52.65 \\
\hline \multirow[t]{2}{*}{$A_{v}$} & $\mathrm{PC}$ & 76.11 & 56.19 & 51.96 & 52.40 & 51.69 & 79.25 \\
\hline & $\mathrm{SC}$ & 58.72 & 21.39 & 21.97 & 22.71 & 21.09 & 51.25 \\
\hline \multirow[t]{2}{*}{$\mathrm{B}_{\mathrm{i}}$} & $\mathrm{PC}$ & 103.91 & 104.88 & 106.25 & 108.93 & 104.81 & 106.55 \\
\hline & $\mathrm{SC}$ & \multicolumn{6}{|c|}{ Disabled } \\
\hline \multirow[t]{2}{*}{$\mathrm{B}_{\mathrm{ii}}$} & $\mathrm{PC}$ & 37.41 & 0 & 9.18 & 34.00 & 0 & 153.73 \\
\hline & $\mathrm{SC}$ & 69.78 & 26.10 & 29.67 & 28.66 & 26.86 & 54.15 \\
\hline \multirow[t]{2}{*}{$B_{v}$} & $\mathrm{PC}$ & 42.25 & 0 & 9.10 & 32.51 & 0 & 156.11 \\
\hline & $\mathrm{SC}$ & 66.58 & 21.01 & 27.69 & 25.43 & 24.81 & 68.24 \\
\hline \multirow[t]{2}{*}{$\mathrm{C}_{\mathrm{i}}$} & PC & 103.91 & 104.88 & 106.25 & 108.93 & 104.81 & 106.55 \\
\hline & $\mathrm{SC}$ & \multicolumn{6}{|c|}{ Disabled } \\
\hline \multirow[t]{2}{*}{$\mathrm{C}_{\mathrm{ii}}$} & $\mathrm{PC}$ & 83.75 & 87.49 & 22.79 & 20.62 & 87.65 & 84.93 \\
\hline & $\mathrm{SC}$ & 85.32 & 88.47 & 21.38 & 18.10 & 85.23 & 88.44 \\
\hline \multirow[t]{2}{*}{$\mathrm{C}_{\mathrm{v}}$} & $\mathrm{PC}$ & 80.40 & 87.65 & 29.78 & 27.27 & 80.00 & 81.50 \\
\hline & $\mathrm{SC}$ & 84.94 & 84.70 & 13.20 & 9.32 & 90.30 & 89.01 \\
\hline
\end{tabular}

With regard to the load-bearing behaviour of the systems, the comparative analysis shows that system configuration $B$ achieves the highest resistance to vertical loading $\left(A_{v}, B_{v}, C_{v}\right)$. The vertical deformation of the systems at mid-span amounts to 11,2 and $8 \mathrm{~mm}$ respectively. The maximum bending moments of the elastic members decrease slightly. The total amount of axial forces developed in the cables also goes through a negligible decrease. In the case of A and B, the primary cables' maximum axial force increases by $1 \%-2 \%$, while the secondary 
cables' axial force increases by $3 \%-5 \%$. The role of the cable elements, both primary and secondary, differs in system configuration $\mathrm{C}$. The primary cables' maximum axial force remains the same, while the secondary cables' axial force increases by $1 \%$.

\section{CONCLUSIONS}

A hybrid cable bending-active structure has been presented in three different configurations with regard to the position of the secondary strut and cable members to the primary members. The structural prototype obtains different arc-like configurations controlled by the supporting secondary cables with variable length. The latter are attached at the periphery of the primary structure, and minimize the need of supplementary external elements for the erection process. The role shifting between the primary and secondary cables demonstrates how the system handles load transfer from one configuration to another and the ability of the primary structure to adapt to variable shapes through its deformation control by the secondary system. Furthermore, all examined system configurations exhibited an adequate load-bearing behaviour under external vertical loading with only minimum deformations.

Compared to conventional catenary structures, the proposed hybrid cable bending-active prototype offers higher flexibility in its configurability. At the same time, gradual cable length modifications of the secondary cables provide target shapes of the system, by avoiding complex and unsafe erection stages. By further extending these principles in shell-like structures composed of multiple girders placed in parallel direction, highly adjustable systems become possible. Along these lines, further research will focus on possible respective hybrid shelllike configurations.

\section{REFERENCES}

[1] Moon, F.C., Franz Reuleaux: Contributions to 19th C. Kinematics and Theory of Machines, Cornell Library Technical Reports and Papers: Ithaca, 2002.

[2] Escrig, F., Emilio perez pinero: inventor of deployability. Structures and Architecture: Concepts, Application and Challenges, Proceedings of Second International Conference on Structures \& Architecture, ICSA2013, ed. P.J.S. Cruz, Guimaraes, pp. 42-57, 2013. http://dx.doi.org/10.1201/b15267-6

[3] Elkhayat, Y.O., Interactive movement in kinetic architecture. Engineering Sciences, 42(3), pp. 816-845, 2014.

[4] Maziar, A., Transformable and Kinetic Architectural Structures: Design, Evaluation and Application to Intelligent Architecture, VDM Verlag: Saarbrucken, 2010.

[5] Schnädelbach, H., Adaptive architecture - a conceptual framework. Proceedings of Media City, Weimar, pp. 523-555, 2010.

[6] Kronenburg, R. (ed), Transportable Environments: International Conference on Portable Architecture, E\&FN Spon: London, 1997.

[7] Gantes, C.J., Deployable Structures: Analysis and Design, WIT Press: Boston, 2001.

[8] Khoo, C.K., Salim, F. \& Burry, J., Designing architectural morphing skins with elastic modular systems. Architectural Computing, 9(4), pp. 379-419, 2011. http://dx.doi.org/10.1260/1478-0771.9.4.397

[9] Hensel, M., Achim, M. \& Weinstock, M., Emergent Technologies and Design: Towards a Biological Paradigm for Architecture, Routledge: Oxford, 2013.

[10] Phocas, M.C., Kontovourkis, O. \& Alexandrou, K., Design of a controlled cable bending-active structure. Proceedings of International Conference on Adaptation and 
Movement in Architecture, ICAMA 2013, eds. C. Ripley \& M. Asefi, Ryerson University: Toronto, pp. 237-249, 2013.

[11] Phocas, M.C., Kontovourkis, O. \& Alexandrou, K., The structural design and construction of a cable bending-active structure. Mobile and Rapidly Assembled Structures IV, eds. N. Temmerman \& C.A. Brebbia, WIT Press: Southampton, 136, pp. 59-70, 2014.

[12] Lienhard, J., Bending-Active Structures: Form-Finding Strategies using Elastic Deformation in Static and Kinetic Systems and the Structural Potentials Therein. Ph.D. Thesis, University of Stuttgart: Stuttgart, 2014.

[13] Liddell, I., Frei otto and the development of gridshells. Case Studies in Structural Engineering, 4, pp. 39-49, 2015.

[14] Veenendaal, D. \& Block, P., An overview and comparison of structural form-finding methods for general networks. Solids and Structures, 49(26), pp. 3741-3753, 2012.

[15] Richard, H., Dickson, M. \& Kelly, O., The use of timber gridshells for long span structures. 8th International Conference on Timber Engineering, WCTE 2004, pp. 1001-1006, 2004.

[16] Happold, E. \& Liddell, W.I., Timber lattice roof for the mannheim bundesgartenschau. The Structural Engineer, 53(3), pp. 99-135, 1975.

[17] Quinn, G. \& Gengnagel, C., A review of elastic gridshells, their erection methods and the potential use of pneumatic formwork. Mobile and Rapidly Assembled Structures $I V$, eds. N. Temmerman \& C.A. Brebbia, WIT Press: Southampton, 136, pp. 129-143, 2014.

[18] SOFISTIK, General Static Analysis of Finite Element Structures. Sofistik Manual, Version 2014-8, Sofistik AG: Oberschleissheim, 2014. 